DOI 10.14746/ssp.2020.4.6

Yuriy ZuLYAR

Irkutsk State University, Russia

ORCID: 0000-0002-9320-519X

Raksana ZULYAR

Irkutsk State University, Russia

ORCID: 0000-0002-9320-519X

Mikhail RyBALKo

Irkutsk State University, Russia

ORCID: 0000-0001-7816-8397

\title{
Становление и развитие современного института губернатора в России (на примере Иркутской области)
}

\begin{abstract}
Аннотация: Исследование процесса создания, становления и развития современной модели российского федерализма обязательно приводит к необходимости анализа института губернатора, являющегося одной из ключевых элементов российской государственности. В течение всего постсоветского периода в системе российского федерализма идет борьба двух тенденций: централизации и децентрализации, в настоящее время доминирует первая. Роль губернатора (главы региона) является ключевой и определяющей во взаимодействии федеральной и региональных властных элит. Спецификой российской модели федерализма является его асимметричность, обусловленная этнической субъектностью. Однако формально главы субъектов РФ имеют равные права и одинаковый круг полномочий. В действительности это не так, но причины этого чисто субъктивны. В каждом субъекте сложилась региональная элита, ориентированная и связанная с правящим классом страны, но не консолидированная внутри мегарегионов. Россия, как реально асимметричная федерация вынуждена уделять большое внимание борьбе с сепаратизмом. В процессе сложных и трудных поисков,руководство страны выработаломодель эффективного федерализма - императивного, при формировании которого был учтен советский опыт. Основным принципом этой модели является соответствие главы региона статусу федерального чиновника, но не представителя, а тем более лидера региональной элиты. Реализация этого принципа весьма трудна, так как находится в противоречии с институтом прямых выборов губернаторов. Однако президент В. В. Путин, владея правом отстранения главы субъекта, строго следит за тем, чтобы они не проводили антигосударственную политику, не имели криминального прошлого и не совершали должностных преступлений. В целях обеспечения эффективного функционирования данной модели, Центр
\end{abstract}


старается не допускать превращения регионов в площадки карьерного роста и делегирует на должности глав субъектов представителей федеральных элит, не связанных с возглавляемыми регионами. При этом особое значение придается его партийности - членство или сочувствие правящей „Единой России”.

Ключевые слова: Российская Федерация, Иркутская область, институт губернатора, российская модель федерализма, Б. Н. Ельцин, В. В. Путин, современная Россия

$\mathbf{P}$ ассматриваемая в статье проблема относится к теме государственной региональной политики. Авторы разделяют точку зрения, определяющую ее как совокупность целей, задач и действий государственных (федеральных и региональных) органов власти, и иных акторов, направленных на создание благоприятных условий для обеспечения пространственного политического и социально-экономического равновесия и развития страны и региона (Animitsa, 2005, c. 7-19).

В политической системе государства есть ключевые центры власти, в Российской Федерации это - прежде всего президент и главы регионов. Развитие российской федеративной системы осуществляется не только на принципах Конституции, но и обусловлено политической традицией и историей государственности, поэтому при изменении формального наименования должности главы региона она воспроизводится постоянно.

Его роль и значение определяется рядом исследователей гигантскойрастянутостью коммуникаций российского пространства, низкой заселенностью и неравномерным освоением,создавшими феномен „географической автономии”, гдеглава региона, олицетворяющий и персонифицирующий власть на и над территорией, действуетсамостоятельно принимая политическиеи хозяйственныерешения (Zamyatin, Zamyatina, 2000, с. 105). Он управляет территорией, сопоставимой с рядом государств. Это объясняет моноцентризм региональных политических режимов, обусловленныйтрадицией российской власти, в которой на уровне архетипов проявляются монархизм и сакрализация власти (Turovskii, 2008, с. 15).

\section{Институт губернатора в России}

Региональный уровень занимает промежуточное положение между федеральным и районным. Отношения между Центром и регио- 
нами в России в значительной степени сводятся к взаимодействию между элитами этих уровней при невысокой роли общества. Поэтому в России выделяют и рассматриваютрегиональный уровень политического процесса в качестве самостоятельного объекта исследования (Dakhin, Raspopov, 1998, с. 134).

До 1992 г. в России только республики имели статус субъекта Федерации, а края и областиявлялись административными территориальными единицами, поэтому губернаторне был главой субъекта РФ. В 1992-1996 гг. в РФ отсутствовала общая практика занятия должности главы региона. Главы субъектов Федерации назначались, другие избирались региональными представительными органами, третьи - в результате общенародных выборов. Лишь в 1996 г. Конституционный суд запретил назначение главырегиона органом представительной власти, вне зависимости от статуса, субъекта РФ. С 1999 г. в российских нормативных актах появилось единое наименование главы региона - „высшее должностное лицо субъекта Российской Федерации)" (Ivanov, 2019, с. 13). Наименование главы региона определяется в субъектах, поэтому есть губернаторы, главы администраций, президент и даже мэр. Губернаторами именуют руководителей толькорусских субъектов (Turovskii, 2008, с. 14, 16).

Восстановление классического института губернатора в Российской Федерации произошло в процессе буржуазно-демократических трансформаций конца 1980-х - начала 1990-х гг., изменивших природу советского народного государства. В результате прямых выборов глав регионов, Москву возглавил Ю. М. Лужков, Санкт-Петербург - А. А. Собчак, и президентом Республики Татарстан, стал М. Ш. Шаймиев (Lysenko, 2004). То естьобщенародное избрание глав произошло только в тех регионах, которыми центр управлять не мог, или элиты которых наоборот, считал для себя опорными и надежными (Москва, Петербург). Переход к губернаторским выборам был непоследовательным, хотя его поддерживали федеральные и региональные элиты и общественность (Turovskii, 2008, с. 15).

\section{Этапы развития}

После подавления августовского 1991 г. путча, президент Б. Н. Ельцин приступил к назначениям глав регионов. Первым таким назначенным администратором стал Ю. А. Ножиков, председатель 
Иркутского облисполкома, который 19 августа 1991 г. выступил против отстранения от власти главы СоветскогоСоюза М. С. Горбачева. Он, от имени исполнительной власти региона, объявил о действии на территории региона только Конституции РСФСР. Ножиков объявил, что в качестве руководителя государства, он признает только президента Ельцина и его указы. После этого руководитель России переподтвердил его статус, наделив полномочиями главы администрации Иркутской области (ИО) (Zulyar, 2013, с. 71). Первым в РФ именование губернатора получил Б. Е. Немцов, распорядившийся после назначенияего главой администрации Нижегородской области (30 нояб. 1991 г.), именовать главу администрации региона губернатором (Skuridin, 2020).

Под предлогом реванша коммунистов, повсеместное введение губернаторских выборов было отложено. В течение года заменили большинство прежних руководителей регионов, осуществив кадровую революцию. Главным критерием назначения были политические и идеологические взгляды кандидата. Из 17 назначенных Президентом глав регионов, впоследствии лишь трое получили поддержку населения в результате прямых выборов. 14 руководителей уступили свои должности в ходе общенародных выборов или передали их опытным управленцам. Вместе с тем, на своих постах остались бывшие советские администраторы, признавшие власть Ельцина летом 1991 г. (Lysenko, 2004). Среди второй группы был и глава администрации Иркутской области Ю. А. Ножиков.Страна поделилась на две части - „выборную” и „централизованную”. Только после переизбрания Ельцина, когда центральные элиты решили свои групповые задачи, были введеныповсеместные губернаторские выборы (Turovskii, 2008, с. 18).

Оппозиция во главе с председателем Верховного Совета РФ Р. И. Хасбулатовым выступила категорически против такой практики возведения в должность глав регионов. Она обвинила Президента в попрании демократических принципов и установлении диктатуры. Начались трудные и долгие переговоры, ибо никто не хотел уступать, в ходе которых удалось найти вариант, который устроил всех. Был установлен порядок, в соответствии с которым, Ельцин выдвигал кандидата региональному представительному органу, и тот, в случае согласия с данной кандидатурой, назначал его на должность главы региона. В результате конкурентной борьбы между Президентом и Верховным советом РФ, в стране сформировался президентско- 
парламентский режим. Он позволил на несколько лет обеспечить баланс сил законодательной и исполнительной власти (Lysenko, 2004), отложив неизбежную схватку противоборствующих сторон.

Логика революционного процесса требовала определиться с основным актором и 20 марта 1993 г. Б. Н. Ельцин ввел особый порядок управления страной, фактически вводивший президентское правление. Эти действия вызвали неоднозначную реакцию в стране. Ряд губернаторов выступил против этих действий. Чтобы испугать колеблющихся Президент отстранил от должности двух протестовавших губернаторов: новосибирца В. П. Муху и Ю. А. Ножикова. В поддержку отстраненных выступила общественность Сибири: в Иркутске состоялся митинг протеста; малый совет Иркутского областного совета охарактеризовал эти действия как неконституционные, его поддержали депутаты Республики Бурятия. Переворот не удался и через два дня Ельцин отменил свое распоряжение, а премьер-министр В. С. Черномырдин принес им извинения.

В результате принятия конституции Российской Федерации (1993 г.) была полностью ликвидирована советская модель региональной власти. Государственная исполнительная власть в субъекте федерации была представлена главой региона, которого назначал Президент. Тем самым завершился период демократической весны в России, сменившийся установлением президентской модели власти. Вместе с тем, победа была неокончательной, и требовала своего закрепления на предстоящих президентских выборах. Опасаясь поражения, и пытаясь обеспечить поддержку регионов за счет назначенных им глав субъектов, Ельциндо середины 1996 г. противодействовал желанию губернаторов закрепить свое положение победой на прямых выборах. У него не было уверенности в том, что после такой легитимации, они сохранят ему верность и окажут поддержку (Lysenko, 2004). Однако не во всех регионах ему удалось реализовать данную установку, в частности в Иркутской области 27 марта 1994 г. прошливыборы депутатов регионального парламента и органов местного самоуправления, а также губернатора, мэров районов, городов и сельских поселений. Действующий глава региона Ю. А. Ножиков, пользовавшийся большой популярностью у населения, организовал плебисцит, и заручился поддержкой 78,16\% избирателей, пришедших на выборы. Закрепив переход к новой форме региональной власти, Законодательное собрание субъекта приняло решение о наименовании высшего должностного лица области - гу- 
бернатором (Zulyar, 2013, с. 71). Расхождение между центром и регионами по процедуре выборов, было вызвано тем, что элиты центра утверждали свою власть, стремясь нейтрализовать вызовы со стороны регионов. А влиятельным региональным лидерам проще было опираться на поддержку населения и местных элит, а не зависеть от переменчивой позиции Центра (Lapina, 2000, с. 63). Изменения в губернаторском корпусе происходят непрерывно, зачастую не совпадая с избирательным циклом. В апреле 1997 г., за год до истечения срока своих полномочий, губернатор Иркутской области Ю. А. Ножиков ушел в отставку. Губернатором был избран Б. А. Говорин - успешный иркутский мэр.

Начиная с 1996 г. во всех регионах страны, кроме Дагестана прошли общенародные выборы глав субъектов России. Это изменило созданную Ельциным модель управления страной, а главное сломало единую вертикаль исполнительной власти и наделило все уровни власти своим объемом полномочий. Прежде всего, это преобразовало статус и мироощущение региональной элиты, и она стала трансформироваться в субъект политического процесса. Этому в значительной степени способствовал принцип формирования Совета Федерации Российской Федерации, в который до начала нулевых годов входили губернаторы и председатели законодательных собраний регионов. На его основе они пытались создать эффективную и демократическую модель российского федерализма. В этот период на равных конкурировали две модели федерализма: централизованная и децентрализованная, хотя сторонники радикального сепаратизма развязали гражданскую войну. В целях сохранения целостности страны, Центр искал механизмы ограничения самостоятельности регионови игнорирования ими общенациональных интересов.

На выборах 2000 г. В. В. Путина победил в подавляющем большинстве регионов, и, он, получив всенародную поддержку, взял курс на понижение политической роли глав субъектов РФ, и на повышение - федеральной бюрократии. Он „равноудалил” губернаторов и олигархов от федеральной власти. В российском федерализме, началось усиление централизации государственного управления (Lysenko, 2004).

Путин приступил к созданию жесткой вертикали власти: организовал семь федеральных округов; установил контроль над губернаторами; вывел из их подчинения силовые и др. федеральные структуры. Губернаторы и председатели заксобраний были удалены из 
верхней палаты парламента, что понизилоих статус с федерального до регионального. Был введен „институт федерального” вмешательства, позволяющий Президенту отстранятьгубернаторов от должности. В Иркутской области 19 августа 2001 г. губернатор Б. А. Говорин на выборах победил лидера местных коммунистов С. Г. Левченко, но в конце 2001 г. сложил с себя полномочия члена СФ (Zulyar, 2013, с. 80$)$.

Следующим важным шагом на пути к созданию новой модели федерализма стало уничтожение финансовой независимости регионов, достигнутое в ходе проведенияреформ А. Л. Кудрина (2004-2005), перенаправившего денежные потоки в Москву. Регионы лишились НДС и природоресурсных налогов, а фискальная нагрузка на сырьевой сектор была перенесена с налогов на экспортные пошлины, идущие в федеральный бюджет (Zachem sovremennoi..., 2019). В результате у регионов возникла бюджетная зависимость от Центра, обеспечившая их политическую лояльность и укрепление вертикали власти. В стране был ликвидирован бюджетный федерализм и независимое местное самоуправление (Deeva, 2013).

В рамках первого президентского срока (2000-2004) В. В. Путин восстанавливал страну и наводил порядок. После переизбрания на второй срок, он инициировал в сентябре 2004 г. отмену прямых выборов глав регионов (Ivanov, 2019, с. 13), не вызвавшую возражений со стороны губернаторов, у которых к осени заканчивался последний срок пребывания у власти (Lysenko, 2004), и они хотели переизбираться на новый. И, на основе президентских рекомендаций, 11 декабря 2004 г. был принят закон, отменивший прямые выборы губернаторов (Dlya kogo..., 2004).

За прошедшие 15 лет страна и общество стали другими, и, прежде всего, сформировались региональные элиты, внутри которых началась борьба за сферы влияния, в том числе политического. Например, в Иркутской области действующий губернатор Б. А. Говорин продавил право избираться на третий срок, устранив двух спикеров регионального парламента. Однако, накал борьбы за право выдвижения, достиг такой степени, что Президент, отклонив предложенные кандидатуры, 13 августа 2005 г. внес на рассмотрение Заксобрания ИО кандидатуру начальника Восточно-Сибирской железной дороги А. Г. Тишанина для наделения его полномочиями губернатора региона. Такая ситуация сложилась в стране впервые. Накал борьбы обеспечили сформировавшиеся в области элиты, не приемлющие 
компромиссов, инспирирующие политические скандалы, озлобленность в обществе, клевету и публичные оскорбления. Третий губернатор ИО Тишанин был утверждён заксобранием региона 26 августа 2005 г. Кандидатура прошла без проблем, в этом случае В. В. Путин опробовал подходы, которые впоследствии стали доминирующими в его региональной политике. Область возглавил человек, прежде не работавший в исполнительной власти (Zulyar, 2013, с. 82, 86). Он не был связан с основными группами интересов внутри региона, не имел корней в области, придерживался технократического стиля управления, не обладал самостоятельным политическим весом, был публично мало известен, и не был ангажирован партиями (Tishanin, Aleksandr..., 2020), но представлял естественную монополию (РАО „Российские железные дороги”) и оказался самым молодым в России губернатором.

Введение практики назначения губернаторов совпало с улучшением в России экономической ситуации и снижением социальной напряженности, что было подано как результат этой практики. Назначения 2005-2012 гг. показали, что известность и популярность кандидата в региональном сообществе почти не учитывалась; назначались „внешние” люди - „варяги”, или местные, но публично не известные. Легкости внедрения этой практики способствовали: опора на действующих губернаторов или на региональные группы влияния; выдвижение представителей крупных федеральных групп влияния; а, иногда „варяги” получали поддержку от „уставшего" населения, а высокий рейтинг Президента, легитимизировал назначения.

В нулевые годы произошлаконсолидациярегиональных элит вокруг Путина, формировалась его клиентела, укреплялисьпозиции Центра по отношению к регионам, и организацияпосредством этого моноцентрического политического режима. К парламентским выборам 2007 г. практически все губернаторы были членами Единой России. В соответствии с логикой властной вертикали, губернаторам передалимеханизмы управления местным самоуправлением, не входящим в систему государственной власти. Губернатор получил право отстранять от должности глав самоуправления и распускать представительные собрания. В результате этих процедур, произошло перераспределение властных полномочий, и теперь и на региональном уровне исполнительная власть доминируетнад представительной (Turovskii, 2008, с. 26-30). 
В апреле 2008 г., накануне премьерства Путина, губернаторская отчетность, включавшая в себя несколькодесятков параметров, характеризующих социально-экономическое положение, перешла в правительство. Летом 2008 г. Минрегион разработал Концепцию совершенствования региональной политики, детализирующую виды ответственности губернаторов перед Центром. Измененная модель взаимоотношений Центра и регионов, поставила во главу угла их способность к кооперации и лояльность федеральной власти. Новая система снизила нагрузку на правительство, за счет передачи некоторых полномочий регионам, превратив тем самым институт губернатора фактически в структурное подразделение федеральной власти.

Но эти меры не смогли полностью устранить контроль губернаторами части федеральной сферы. А, мониторингих деятельности полномочными представителямипрезидента и главными федеральными инспекторами - оказался неэффективным. В авторитарных региональных режимах силовые и надзорные структуры сращивались с местными чиновниками, а последние становились клиентелой федеральныхадминистраторов. Губернаторов не удалось поставить под контроль местной представительной и партийной власти,а неудавшаяся в конце 1990-х гг. попытка использовать местное самоуправление для ограничения региональной власти, вынудила Центр подчинить его губернаторам. Главы регионов обладают реальной автономией, но в разной степени, что позволяет классифицировать региональные политические режимы (Kuz'min, Melvin, Nechaev, 2002, c. 144).

Начав избавляться от прежних региональных управленческих элит, и лишая регионы самостоятельности, Центр разрушалместные системы управления, что вело к проблемам для федералов. Поэтому правящий класс решил вернуться к прямым выборам глав регионов (Deeva, 2013). Это демонстрируют события в Иркутской области, где в апреле 2008 г. „варяг” - губернатор Тишанин подал заявление об отставке и получил ее уже 15 апреля (Putin prinyal otstavku, 2008). Причиной отставки стал неразрешимый конфликт с региональными элитами. Однако, президент Путин назначил временно исполняющим обязанности губернатора очередного „варяга” И. Э. Есиповского, ставшего последним главой региона, которого рекомендовал президент Путин (Рopov, 2008). Новый глава региона, используя все средства, сформировал лояльное себе Законодательное собрание, но не успел воспользоваться результатами победы, так как погиб при 
странных обстоятельствах в ночь на 10 мая 2009 г. в результате крушения вертолета на территории Прибайкальского национального парка (Medvedev vydvinul..., 2009).

28 мая 2009 г. президент Д. А. Медведев, внес на рассмотрение ЗС Иркутской области кандидатуру зампредседателя Совета Федерации Д. Ф. Мезенцева (Utverzhdenie novogo ..., 2009) - очередного „варяга”. Сессия Закссобрания 8 июня 2009 г. наделилаего полномочиями губернатора региона. Его кандидатуру поддержали все депутаты, присутствовавшие на заседании (Nadelyat' budut..., 2009). Но, в апреле 2012 г. губернатор Мезенцев обратился к президенту РФ с просьбой об отставке, и 18 мая Путин подписал указ о досрочном прекращении его полномочий (Gubernator Irkutskoi oblasti..., 2012). Причиной отставки опять стал непримиримый конфликт с региональными элитами.

16 января 2012 г. Д. А. Медведев внес в Госдуму законопроект, вернувший россиянам право напрямую выбирать глав регионов, а политическим партиям - выдвигать кандидатов в губернаторы. Закон вступил в силу с 1 июня 2012 г., но Путин 18 мая 2012 г. успел назначить исполняющим обязанности губернатора Иркутской области С. В. Ерощенко. В соответствии с процедурой, президиум генсовета партии „Единая Россия” 23 мая 2012 г. представил президенту РФ три кандидатуры на пост губернатора. Путин рекомендовал Ерощенко, и 29 мая 2012 г. тот был утвержден в должности губернатора (Nazvany kandidaty..., 2012).

Серия отставок и назначений глав ключевых российских регионов, произведенная до вступления в силу закона о выборах губернаторов,свидетельствует о стремлении Центра сформировать послушный губернаторский корпус. Возвращение всенародных выборов глав регионов было вынужденной мерой для сохранения существующего политического режима и появления у Центра уверенности в управляемости страной (Deeva, 2013).

Глав регионов стали избирать в всенародно, но кандидаты в обязательном порядке проходят „президентский фильтр”. Президент также может отстранить своим указом главу региона за недобросовестное исполнение своих обязанностей или подозрения в совершении преступления. Для поддержки прокремлевских губернаторов, в 2015 г. принят закон, по которому губернаторские сроки отсчитывались с 2012 г., обнуляя предыдущие (Skuridin, 2020). Каждый регион находится в зоне интересов определенных провластных 
группировок и структур. Лидеры крупных элитных групп активно участвуютв назначении губернаторов, что препятствует избранию случайных людей. Но, это не дает полной гарантии, свидетельством этого является карьерная судьба очередного назначенца-губернатора в Иркутскую область. 3 мая 2015 г. С. В. Ерощенко по собственному желанию был освобождён от занимаемой должности и назначен врио губернатора ИО. Будучи уверенным в своей победе, он в сентябре 2015 г. пошел на выборы и проиграл коммунисту С. Г. Левченко.

\section{Современный период 2018-2020 гг.}

Действующая в РФ модель императивного асимметричного федерализма была сформирована для противодействия децентрализации (Zulyar, 2013, c. 306; Rodionova, 2008, с. 28), существовавшей на рубеже веков. В ее основе лежат интеграционные начала, но внутренняя и внешняя политика определяются Центром. Это формализует принципы федерализма и усиливает централизацию, препятствуя проведению главами субъектов Федерации несогласованной с Центром политики. Помимо решения управленческих задач, онаобеспечивает доминирование правящего класса. Вместе с тем, не все главы регионов РФ играют роль лишь проводников политики определенных кланов, некоторые сами являются членами правящего класса. Среди них - губернаторы, имеющие личные связи с Президентом и, соответственно, обладающие сильным лоббистским потенциалом (Deeva, 2013).

Идея укорененности губернатора в регионенеприемлема для Кремля, отсюда и противодействие карьеререгиональных политиков. В настоящее время регион - это не то место, где вырастают политики, проходя все ступени карьеры. Даже если назначенный губернатор оттуда родом, он все равно оказывается в нем чужаком. Например, в Бурятии или Калмыкии новые руководители местные „по паспорту”, но на деле они посторонние для населения и местных элит, что чревато кризисными ситуациями и массовыми протестам.

В современной России у большинства губернаторов нет авторитета среди жителейи в администрации президента. С помощью избирательных технологий можно сделать губернатором любого, поддерживаемого Кремлем. Но, даже голосующие за креатуру Центра, впоследствии не демонстрируют лояльности губернатору, и не 
готовы разделить с ним ответственность за ситуацию в регионе. Значительная часть игнорирующих выборы, делает это в знак протеста. Губернатор в глазах Центра - просто чиновник, работающий далеко от Москвы. Современная модель российской региональной политики культивируетслабых губернаторов - взаимозаменяемых чиновников, которые решают два типа задач, ни одна из которых не идет на пользу регионам: быстро выслужиться и продолжить карьеру или сидеть, ожидая указаний от начальства. Поэтому население регионов во всех проблемах обвиняет Центр (Pochemu v sovremennoi..., 2019). Институт губернатора в РФ ослабляется уже 15 лет, так как Центр склоняется к тому, что территории должны быть послушны и подконтрольны, а также недостаточнобогаты для самостоятельности.

Но, далеко не все аналитики разделяют эту точку зрения, так как Центральная власть всегда нуждается в поддержке населения, особенно в федерации. А она, в значительной степени, зависит от работы губернаторов. Поэтому главный из 15 критериев работы глав регионов - уровень поддержки населением федеральной власти (Zachem sovremennoi..., 2019). А, для этого главы регионов должны быть эффективными управленцами (Byt' $i l i$ ne byt'..., 2019). Приведение губернаторского корпуса в надлежащее состояние производилось весь период. В русле данной политики 12 декабря 2019 г. Президент РФ Путин добился отставки губернатора Иркутской области коммуниста С. Г. Левченко. Просьба Левченко об отставке стала неожиданной для населения и аналитиков, так, так он отвергал эту идею, да и до сентябрьских выборов 2020 г. оставалось немного. Но, Центр решил дать своему назначенцу время показать себя. Формальная причина недовольства президента - неудачная работа губернатора в пережившем наводнение Тулуне. Но, все понимали, что это только повод. 12 декабря 2019 г. генерал-лейтенанта МЧС И. И. Кобзева назначили врио главы Иркутской области (Prezident Rossii Vladimir..., 2019). Досрочные выборы губернатора состоялись 13сентября 2020 г. Губернатором достаточно легко избрали И. И. Кобзева, получившего 60,79\% голосов (Irkutskim gubernatorom ..., 2020). Показательна история института губернатора в Иркутском регионе, здесь из восьми губернаторов только один занимал эту должность весь срок. Причинами нестабильности первых должностных лиц, являлись их неэффективность, конфликтность, оппозиционность или совокупность этих качеств. Политическая культура иркутян ориентирована на 
борьбу с губернаторами-назначенцами, и они грамотно используют неизбежные ошибки, допускаемые руководителями, не погруженными в политическое пространство региона и его специфику.

Влияние губернатора на социально-экономическую ситуацию в регионах РФ невелико и ограничено (Turovskii, 2008, с. 28). Да, и сложно эффективно и по-особенному руководить регионом, который является частью унифицированной и централизованной страны (Pochemu v sovremennoi..., 2019). В настоящее время, несмотря на реально существующую практику общенародного избрания глав регионов, Центр разработал и эффективно использует практику их назначения.

Для обеспечения экономической и социальной стабильности, нужны эффективные администраторы. Кандидаты на губернаторские должности подбираются Центром среди федеральных чиновников, госкомпаний, „силовиков” и успешных губернаторов (Institut gubernatorstva ..., 2019). Для определения эффективности губернаторов используется система оценки их деятельности. В декабре 2018 г. Президент утвердил новый перечень ее критериев, снизив число показателей с 24 до 15 (Gorodetskaya, 2018). Начавшееся в марте 2020 г. обновление губернаторского корпуса, произошло в результате запроса населения на смену руководства и улучшение социально-экономической ситуации. Средний возраст новых руководителейсоставил 48 лет, в среднем они на 13 лет моложе предшественников. Востребованы губернаторы-хозяйственники и управленцы, а не политики. Растетчислогубернаторов с федеральным опытом, репутация губернатора - ставленника Центра перестает быть негативной в глазах населения, пришедшего к выводу,что глава, имеющий личные знакомства с чиновниками высокого уровня и главами госкорпораций, способен привлечь в регион инвесторов и трансферты.

Современный губернатор мотивирован на результат и социально-экономическое развитие региона. Онистали уделять больше внимания развитию инфраструктуры и активнее используют государственно-частное партнерство. Главы регионов ориентированы на рост эффективности расходовна дорожный фонд и здравоохранение, на поддержку отечественного производителя, развитие аграрного сектора (Fedorov, 2019).

Вместе с тем, сложности губернаторства слабо компенсируются перспективами продолжения своей карьеры: большая политика, бизнес, отставка или тюрьма - вот основные варианты. Смена одного 
губернаторского кресла на другое - из разряда исключений (Zachem sovremennoi..., 2019). Недавнее исследование фонда „Петербургская политика" показало, что лишь чуть более $10 \%$ губернаторов, могут рассчитывать на карьерный рост. Из 100 губернаторов, ушедших в отставку с 2011 г., только 13 прочно обосновались в Москве (Byt' ili ne byt'..., 2019). Хороший вариант - сенаторское кресло, на него ориентированы губернаторы старшего поколения, ищущие спокойной жизни. Следующий - большой бизнес или госкорпорация, что возможно, если глава на хорошем счету у Центра (Institut gubernatorstva..., 2019).

Анализ политики руководства РФ по формированию института губернатора в стране свидетельствует, что все 30 лет постсоветского периода, она постоянно находилась в поле зрения президентов. Авторы выделяют не менее десяти этапов ее становления, развития и последующих трансформаций.

Непрерывно ведется поиск оптимальной модели российского федерализма, как внутри правящего класса, так и между центром и регионами. Максимальной свободой, правами и возможностями главы регионов обладали во второй половине 1990 гг. - начале 2000 гг., а минимальными в 2005-2012 гг.

Возвращение с 2012 г. прямого избрания глав регионов, сопровождалось установлением модели императивного асимметричного федерализма. В ней максимально формализованы его принципы, усилена централизациявсех сфер жизнедеятельности. Данная модель затрудняет проведение главами субъектов РФ самостоятельной политики. Как и процесс демократизации в целом, практика выборности губернаторов является крайне неустойчивой и обратимой тенденцией. Сейчас доминирует практиказанятия должности главы региона молодыми, амбициозными и ориентированными на эффективность и карьерный рост управленцами-хозяйственниками.

\section{Bibliography}

Animitsa E. G. (2005), Regional'naya politika: sushchnost', osnovnye tseli, problemy, "Ekonomika regiona", № 1.

Byt' ili ne byt': institut gubernatorstva okazalsya na rasput'e (2019), "Novye izvestiya", https://yandex.ru/turbo/newizv.ru/s/article/tilda/13-05-2019/bytili-ne-byt-institut-gubernatorstva-okazalsya-na-rasputie, 12.12.2020. 
Dakhin A. V., Raspopov N. P. (1998), Problema regional'noi stratifikatsii v sovremennoi Rossii, "Polis", № 4.

Deeva D. M. (2013), Institut gubernatorstva v strategiyakh rossiiskoi vlasti, "Vlast"”, № 4, https://cyberleninka.ru/article/n/institut-gubernatorstva-v-strategiyahrossiyskoy-vlasti, 14.12.2020.

Dlya kogo zakon podpisan (2004), "Rossiiskaya gazeta", 15.12.

Fedorov L. (2019), Chto nuzhno umet', chtoby stat' gubernatorom v sovremennoi Rossii, https://ura.news/articles/1036277813, 10.12.2020.

Gorodetskaya N. (2018), Gubernatory poluchat novye otsenki, "Kommersant", 20.12.

Gubernator Irkutskoi oblasti D. Mezentsev dosrochno ushel v otstavku (2012), "RBK", https:/www.rbc.ru/politics/18/05/2012/5703f7b09a7947ac81a68113, 13.12.2020.

Institut gubernatorstva na rasput'e: byt'ili ne byt'? (2019), "Novye Izvestiya", https:// newizv.ru/article/tilda/13-05-2019/byt-ili-ne-byt-institut-gubernatorstvaokazalsya-na-rasputie, 9.12.2020.

Irkutskim gubernatorom ofitsial'no stal Igor'Kobzev (2020), "Rusbalt", https://www. rosbalt.ru/russia/2020/09/18/1864009.html, 13.12.2020.

Ivanov V. (2019), Glava sub'ekta Rossiiskoi Federatsii. Istoricheskoe, yuridicheskoe i politicheskoe issledovanie. Istoriya gubernatorov, V. 2 t. T. 1. V. 2 kn. Kn. 1., Moskva, Publ. Izdanie knig kom.

Kuz'min A. S., Melvin N. Dzh., Nechaev V. D. (2002), Regional'nye politicheskie rezhimy v postsovetskoi Rossii: opyt tipologizatsii, "Polis", № 3.

Lapina N. Yu. (2000), Strategiya regional'nykh elit: ekonomika, modeli vlasti, politicheskii vybor, INION RAN, Moskva.

Lysenko V. N. (2004), Institut gubernatorov v sovremennoi Rossii: vpered v proshloe, "Kazanskii federalist”, № 4 (12), http://www.kazanfed.ru/publications/ kazanfederalist/n12/13/, 11.12.2020.

Medvedev vydvinul na post Irkutskogo gubernatora senatora Mezentseva, "ne uslyshav” polpreda (2009), RIA Novosti, https://ria.ru/20090528/172603252. html, 12.12.2020.

Nadelyat' budut v sleduyushchii ponedel'nik (2009), http://irkutsk.aldana.ru/new/ view/id/14356, 12.12.2020.

Nazvany kandidaty na post gubernatora Irkutskoi oblasti (2012), http://www.irk.ru/ news/20120523/candidates/, 7.12.2020.

Pochemu v sovremennoi Rossii ne mozhet byt' khoroshego gubernatora (2019), "Vedomosti", https://www.vedomosti.ru/opinion/columns/2019/10/29/ 814976-pochemu-v-sovremennoi-rossii-mozhet-bit-horoshego-gubernatora, 13.12.2020.

Popov A. (2008), Neozhidannaya zakonomernost', https:/expert.ru/2008/11/21/ esipguber/, 1.12.2020.

Prezident Rossii Vladimir Putin prinyal otstavku Sergeya Levchenko s posta gubernatora (2019), https://www.bfm.ru/news/431806?utm_source=yxnews 
\&utm_medium=desktop\&utm_referrer=https $\% 3 \mathrm{~A} \% 2 \mathrm{~F} \% 2 \mathrm{Fyandex}$. ru\%2Fnews, 11.12.2020.

Putin prinyal otstavku gubernatora Irkutskoi oblasti A. Tishanina i naznachil vrio gubernatora I. Esipovskogo (2008), "Lenta.ru”, http://lenta.ru/lib/14164254/, 12.12.2020.

Rodionova A. K. (2008), Osnovnye modeli rossiiskogo federalizma, "Nauchnoanaliticheskii zhurnal obozrevatel' - Observer”, № 11.

Skuridin D. (2020), Gubernatory kak sotsial'nyi institut. Istoriya $i$ perspektivy, "Gubernatory.ru”, https://governors.ru/expert/Dmitriy-Skuridin/Gubernatorykak-soczialnyy-institut-Istoriya-i-perspektivy/89, 13.12.2020.

Tishanin, Aleksandr. Byvshii gubernator Irkutskoi oblasti (2020), http://lenta.ru/lib/ 14164254/, 10.12.2020.

Turovskii R. F. (2008), Institut gubernatora v Rossii: sovremennaya evolyutsiya i perspektivy, "Regional'naya Rossiya-2008: politika, delovoi klimat i sotsial'nye protsessy $\mathrm{v}$ sravnitel'noi perspective", Publ. VVAGS, Nizhnii Novgorod.

Utverzhdenie novogo gubernatora Irkutskoi oblasti (2009), http://www.irk.ru/news/ subjects/19/, 12.12.2020.

Zachem sovremennoi Rossii nuzhny gubernatory (2019), https://vostokmedia.com/ news/politics/14-05-2019/zachem-sovremennoy-rossii-nuzhny-gubernatory, 10.12.2020.

Zamyatin D. N., Zamyatina N. Yu. (2000), Prostranstvo rossiiskogo federalizma, "Polis", № 5.

Zulyar Yu. A. (2008), Politologiya, V 2. t. T. 1., Publ. ISU, Irkutsk.

Zulyar Yu. A. (2013), Vosstanovlenie i razvitie instituta gubernatorskoi vlasti v regione, "Sovremennaya istoriya Irkutskoi oblasti", V 2 t. T. 2. Ch. 1., Publ. ISU, Irkutsk.

\section{Powstanie i rozwój nowoczesnej instytucji gubernatora w Rosji (na przykładzie obwodu irkuckiego)}

\section{Streszczenie}

Badanie procesu tworzenia, kształtowania i rozwoju współczesnego modelu federalizmu rosyjskiego nieuchronnie prowadzi do konieczności analizy instytucji gubernatora, która jest jednym z kluczowych elementów państwa rosyjskiego. W okresie poradzieckim w systemie federalizmu rosyjskiego istniały dwa nurty: centralizacja i decentralizacja; obecnie dominuje ten pierwszy. Rola gubernatora (głowy regionu) jest kluczowa i decydująca w relacjach między federalnymi i regionalnymi elitami władzy. Specyfiką rosyjskiego modelu federalizmu jest jego asymetria wynikająca z podmiotowości etnicznej. Jednak formalnie szefowie regionów Federacji Rosyjskiej 
mają równe prawa i taki sam zakres uprawnień. Rzeczywistość jest inna, ale przyczyny tego są czysto subiektywne. Elity poszczególnych regionów są zorientowane na centralną klasę rządzącą kraju i są z nią powiązane, ale nie są skonsolidowane w ramach megaregionów. Rosja, jako prawdziwie asymetryczna federacja, musi walczyć z separatyzmem. W procesie skomplikowanych i trudnych badań władze kraju wypracowały imperialny model efektywnego federalizmu, w którego tworzeniu wzięto pod uwagę doświadczenia z okresu Związku Radzieckiego. Główną zasadą tego modelu jest to, że status szefa regionu odpowiada statusowi urzędnika federalnego, ale nie przedstawiciela, a tym bardziej lidera regionalnej elity. Realizacja tej zasady jest wysoce problematyczna, ponieważ jest ona sprzeczna z instrumentem bezpośrednich wyborów gubernatorów. Jednak prezydent Putin, który ma prawo do usunięcia głowy każdego regionu sprawuje pieczę nad tym, aby poszczególne osoby nie prowadziły polityki antypaństwowej, nie popełniały przestępstw urzędowych, ani nie miały kryminalnej przeszłości. W celu zapewnienia efektywnego funkcjonowania tego modelu, centrum stara się nie dopuścić do przekształcania się regionów w platformy budowania własnych karier i deleguje na stanowiska kierownicze przedstawicieli elit federalnych niezwiązanych z regionami. Jednocześnie szczególne znaczenie przywiązuje się do ich postaw, przejawiających się członkostwem lub sympatią do rządzącej partii Jedna Rosja.

Słowa kluczowe: Federacja Rosyjska, obwód irkucki, stanowisko gubernatora, rosyjski model federalizmu, Borys N. Jelcyn, Władimir W. Putin, polityka regionalna

\section{The formation and development of the modern institution of governor in Russia (on the example of the Irkutsk region)}

\section{Summary}

The study of the creation process, formation and development of the contemporary model of Russian federalism requires an analysis of the institution of governor, which is one of the key elements of the Russian state. In the post-Soviet period, there were two trends within the Russian federalist system: centralization and decentralization; currently the former is dominant. The role of governor (head of the region) is essential and decisive in the interaction between the federal and regional power elites. However, formally, the heads of regions of the Russian Federation have equal rights and the same range of powers. In reality, this is not the case, but the reasons for this are purely subjective. The elites in every region are oriented towards and associated with the country's ruling class, but not consolidated within megaregions. In the course of complex and difficult search, the country's leadership developed an imperial model of effective federalism, in the formation of which the Soviet experience was taken into account. The main principle of this model is that the status of a head of the region corresponds to that of a federal official but the former is not a representative of the regional elite and much less its leader. It is highly problematic to implement this principle as it contradicts the instrument of direct elections of governors. However, Presi- 
dent Putin, who has the right to remove the head of any region, guarantees that they do not pursue any anti-state policy or commit official crimes, and that they do not have criminal past. In order to ensure the effective functioning of this model, the center tries to prevent the transformation of regions into platforms for developing individual careers and delegates the representatives of federal elites who are not associated with the regions as their heads. At the same time, special importance is given to their partisanship reflected by their membership of or sympathy for the ruling United Russia.

Key words: Russian Federation, Irkutsk region, governor's office, Russian model of federalism, Boris N. Yeltsin, Vladimir V. Putin, regional policy 